\title{
LIMITES DO NEXO DE CAUSALIDADE EXISTENTES ENTRE A RESPONSABILIZAÇÃO DOS HOSPITAIS PELO INSUCESSO DE CIRURGIAS E AS CONDIÇÕES GERAIS DE SAÚDE
}

\author{
EXISTING CAUSALITY NEXT LIMITS BETWEEN HOSPITALS \\ 'RESPONSIBILITY FOR SURGERY FAILURE AND GENERAL HEALTH \\ CONDITIONS
}

\author{
FLÁVIA PIVA ALMEIDA LEITE ${ }^{1}$ \\ MIGUEL KFOURI NETO ${ }^{2}$ \\ BEATHRYS RICCI EMERICH ${ }^{3}$
}

\section{RESUMO}

O projeto intitulado, "Limites do nexo de causalidade existentes entre a responsabilização dos hospitais pelo insucesso de cirurgias e as condições gerais de saúde" trata da discussão acerca dos limites do nexo de causalidade existentes entre a responsabilidades das instituições hospitalares e as péssimas condições gerais de saúde oferecidas pelo governo brasileiro. Apesar de não ser um tema novo, os direitos dos hospitais no tocante a relação hospital-paciente e hospital-recursos tornam-se o centro das atenções como elemento definidor não só de uma nova era da sociedade, mas também de uma revisão antropológica da relação direitos fundamentais - limites do nexo de causalidade. O presente estudo objetiva investigar os limites do nexo de causalidade existentes entre a responsabilização do hospital e a escassez de recursos oferecidos pelo governo, nos casos de insucessos de procedimentos cirúrgicos. Dentre os objetivos específicos, a pesquisa visa trazer os conceito e histórico da responsabilidade civil; demonstrar os fundamentos no Código Civil e no Código de Defesa do Consumidor; diferenciar a responsabilidade civil subjetiva da objetiva; esclarecer qual a natureza jurídica da relação hospital/paciente; apontar quais as obrigações do hospital; esclarecer qual a responsabilidade civil do hospital frente ao insucesso de procedimentos cirúrgicos; identificar a aplicação do Código de Defesa do Consumidor e do Código Civil nas instituições hospitalares, bem como as condições gerais das instituições públicas hospitalares; e, por fim, apontar quais os limites do nexo causal em procedimentos cirúrgicos mal sucedidos. O estudo bem sendo realizado mediante a abordagem qualitativa que se caracteriza pela pesquisa primária documental, com o intuito de ampliar os conhecimentos, fundamentando-se no estudo de referenciais teóricos, tendo empregado onde as contradições se transcendem dando origem a novas contradições que requerem soluções. No ponto de vista dos objetivos metodológicos deste estudo, o tipo de pesquisa que é exploratória com vista a proporcionar maior familiaridade com um problema em razão de escolhermos para procedimentos técnicos de investigação o levantamento bibliográfico, elaborada a partir de consultas acerca do entendimento de constitucionalistas e juristas e empreendedores sobre a aplicabilidade dos limites do nexo de causalidade nas instituições hospitalares frente ao insucesso em procedimentos cirúrgicos, bem como utilização de artigos acadêmicos em sítios da internet

\footnotetext{
${ }^{1}$ Doutora em Direito Urbanístico pela Pontifícia Universidade Católica - PUC - São Paulo/SP, Mestre em Direito Constitucional pela Instituição Toledo de Ensino - ITE - Bauru/SP, Pós-graduada em Gerente de Cidades pela Fundação Armando Álvares Penteado - FAAP - São Paulo/SP. Docente da UNESP - Universidade Estadual Paulista "Julio de Mesquita Filho", Faculdade de Arquitetura, Artes e Comunicação - Campus Bauru. Docente permanente do Programa de Pós-Graduação em Direito da UNESP- Franca. E-mail: flavia.leite @ unesp.br ${ }^{2}$ Doutor em Direito das Relações Sociais pela PUC-SP. Mestre em Direito pela UEL. Professor do Programa de Mestrado em Direito Empresarial e Cidadania do Centro Universitário Curitiba- UNICURITIBA.

${ }^{3}$ Advogada e mestranda em Direito Empresarial e Cidadania pelo Centro Universitário Curitiba UNICURITIBA. Membro do Grupo de Pesquisa Direito da Saúde e Empresas Medicas, liderado pelo Professor Doutor Miguel Kfoury Neto, registrado no CNPq.
} 
apropriados. Assim, a metodologia a ser adotada será a dedutiva, isto é, análises de doutrinas, artigos e legislações. Além disso, será empregado o método indutivo devido com a análise de jurisprudências acerca do tema até o presente momento. O estudo de tal temática, tão vasta e complexa representa um desafio, como demonstram as diversas investigações multidisciplinares das áreas, que, sob diferentes enfoques e perspectivas, vêm continuamente tentando avançar a compreensão teórica do assunto. $\mathrm{O}$ estudo deste fenômeno e sua aplicabilidade na esfera juslaboral exigem prévia contextualização do instituto e sua evolução no tempo como condição para entender seus fundamentos, sua função teleológica, e, por fim, a verificação da sua efetividade sob o viés da proteção dos direitos fundamentais da saúde. O estudo em questão pretende contribuir para o entendimento de que a saúde deve ser compreendida como qualidade de vida e não apenas como ausência de doenças. E, isso deve ser garantido por políticas sociais e econômicas, reduzindo o risco de doenças e promovendo o acesso universal e igualitário às ações e serviços para promoção, proteção e recuperação da saúde.

Palavras-chave: responsabilidade civil; limites do nexo causal; responsabilidade civil dos hospitais; escassez de recursos do governo; condições gerais de saúde.

\begin{abstract}
:
The paper entitled "Bounds of the causal connection between the responsibility of hospitals for the failure of surgeries and poor conditions of the population" discusses the boundaries of the causal link between the responsibilities of hospital institutions and poor general conditions offered by the Brazilian government. Though this is not a new topic, the rights of hospitals concerning hospital-patient relationship and hospital-resource relationship have become a key factor to define not only a new age of society but also an anthropological review of the relationship between fundamental rights. This study aims to investigate the bounds of the causal connection between hospital liability and the lack of resources offered by the government in cases of surgical treatment failure. Among the specific objectives, the research aims to present concepts related to the civil liability and its historical aspects; to show the Fundamentals of Civil Law and Consumer Protection Law; to investigate the differences between subjective liability and objective liability; clarify the legal nature of the hospital-patient relationship; point out the hospital's duties, clarify what is the liability of hospitals in the light of the surgical treatment failure; identify what the Civil Law and Consumer Protection Law establish regards hospital institution, as well, identify the public hospital conditions; and, finally, point out the bounds of the causal connection of the responsibility of hospitals in the light of unsuccessful surgeries. The study has been carried out through a qualitative approach characterized by primary documentary research to expand knowledge, based on the study of theoretical references used where the contradictions lead to new contradictions that require solutions. From the methodological point of view, this is an expanded research that aims to increase familiarity with a new problem. For this reason, we choose as survey procedure a bibliographical research. This bibliographical survey will be elaborated from consultations about the understanding of constitutionalists, jurists and entrepreneurs on the applicability of bounds of the causal connection in the hospitals in the light of unsuccessful surgeries. The bibliographical survey will also use academic articles on appropriate websites. Thus, the methodology used in this study is deductive, that is, an analysis of legal doctrines, articles and legislation. Furthermore, the inductive method will also be used with the analysis of jurisprudence on the subject up to the present. The study of such a broad and complex topic represents a challenge, as demonstrated by the diverse multidisciplinary investigations of the areas, which, under different approaches and perspectives, have been continuously trying to advance the theoretical understanding of the subject. The study of this phenomenon and its applicability in labor law require prior contextualization of the topic and its evolution over time as a condition to understand its fundamentals and its teleological function. Finally, this study requires the verification of its effectiveness taking into account the protection of the fundamental health rights. The study in question aims to contribute to the understanding that health should be seen as quality of life and not just as the absence of disease. And this must be guaranteed by social and economic policies, reducing the risk of diseases and promoting universal and equal access to programs and services for promoting, protecting and recovering health.
\end{abstract}

Key-words: civil liability; bounds of the causal connection; hospital liability; lack of resources offered by the government; health conditions. 


\section{INTRODUÇÃO}

O presente trabalho tem o objetivo de abordar a responsabilidade civil é no campo do Direito com a finalidade analisar e determinar os deveres de ressarcimento pelos atos injustos praticados pelas instituições hospitalares e perante o Estado. O Estado é um ente criado pelos membros da sociedade com o fim de garantir-lhes a proteção dos bens juridicamente tutelados. E, assim, por meio da lei, limita a liberdade individual, coibindo as intervenções injustas nas vidas dos particulares.

Dessa forma, faz-se conveniente fazer uma demonstração analítica dos requisitos que têm de estar presentes para que se possa falar em responsabilidade civil dos hospitais e estabelecimentos de saúde. Para isso, primeiramente, o trabalho cumprirá esclarecer que a questão da responsabilidade civil e seu histórico, bem como a diferenciação das responsabilidades subjetivas e objetivas.

A doutrina entende que a obrigação prestada pelo hospital é classificada como sendo "de meio", cabendo, portanto, a ele, fornecer os meios necessários ao correto atendimento do paciente. Todavia, a problemática que este trabalho pretende identificar é "qual o limite do nexo de causalidade das instituições hospitalares nos casos em que procedimentos cirúrgicos malsucedidos por falta de escassez de recursos oferecidos pelo governo?".

Nesse sentido, buscando uma maior compreensão acerca da temática envolvida, em seguida o trabalho ainda pretende esclarecer a responsabilidade civil dos hospitais e explicar quais suas obrigações perante o insucesso desses procedimentos cirúrgicos ante a falta de recursos necessários para sua realização, para que, assim, se chegue a indagação pretendida.

Feitas essas ponderações introdutórias, pode-se constatar a complexidade e a relevância da questão objetivada neste trabalho, pelo qual não tem o desígnio de esgotar o assunto, mas apenas, de trazer alguns apontamentos iniciais e importantes acerca dos limites do nexo causal das instituições hospitalares ante o fracasse em um procedimento cirúrgico.

\section{RESPONSABILIDADE CIVIL}

\subsection{CONCEITO E HISTÓRICO}

A responsabilidade civil parte do posicionamento que todo aquele que violar um dever jurídico através de um ato lícito ou ilícito, tem o dever de reparar, pois todos temos um dever 
jurídico originário o de não causar danos a outrem e ao violar este dever jurídico originário, passamos a ter um dever jurídico sucessivo, o de reparar o dano que foi causado 4 .

Segundo Gagliano5 , o termo "Responsabilidade" tem origem no verbo do Latim Respondere, que significa então que quando alguém diante uma ação ou omissão causa um dano tem a obrigação de responder, este assume as consequências causadas pelo dano.

Nas palavras do Doutor em Direito, Francisco Cardozo Oliveira:

\begin{abstract}
"A causalidade no direito, ligada ao problema da ordem do justo e as incertezas que ela provoca, pode ser tomada como um elemento aglutinador, capaz de fazer emergir o modo como a forma de pensamento jusnaturalista elabora os fundamentos do direito e seus retornos. É bem provável que a questão da causalidade, que até hoje surge envolta em dúvidas e que atravessa os fundamentos do direito desde, por exemplo, a relação entre fato e norma, até seus reflexos na responsabilidade civil e na teoria do crime, constitua um dos elementos centrais na ordenação do direito e na titularização de direitos. $" 6$
\end{abstract}

Outrossim, San Tiago Dantas ${ }^{7}$ define que o principal objetivo da ordem jurídica é "proteger o lícito e reprimir o ilícito." Portanto, ao mesmo tempo em que ela se empenha em tutelar a atividade do homem que se comporta de acordo com o Direito, em contraponto ela reprime a conduta daquele que a contraria.

De acordo com Carlos Roberto Gonçalves ${ }^{8}$ : "a responsabilidade civil tem, pois, como um de seus pressupostos, a violação do dever jurídico e o dano. Há um dever jurídico originário, cuja violação gera um dever jurídico sucessivo ou secundário, que é o de indenizar o prejuízo. ,

Ainda, segundo Maria Helena Diniz ${ }^{9}$, a responsabilidade civil pode ser definida como sendo:

\footnotetext{
"a aplicação de medidas que obriguem alguém a reparar dano material ou moral causados a terceiros em razão de ato do próprio imputado, de pessoa por quem ele responde, ou de fato de coisa ou animal sob sua guarda (responsabilidade subjetiva), ou, ainda, de simples imposição legal (responsabilidade objetiva). ”
}

\footnotetext{
${ }^{4}$ CAVALIERI FILHO, Sérgio. Programa de Responsabilidade Civil, São Paulo: Atlas, 2008, p. 02.

${ }^{5}$ GAGLIANO, Pablo Stolze. Novo Curso de Direito Civil: Responsabilidade Civil. São Paulo: Saraiva, 2011, p. 43-44.

${ }^{6}$ OLIVEIRA, Francisco Cardozo; OLIVEIRA, Nancy Mahra de Medeiros Nicolas. Leis, Serpentes e Baratas: análise reconstrutiva da sobrevivência das formas de fundamentos do Direito Moderno e seus efeitos na realidade brasileira. SEQUÊNCIA (UFSC), v. 40, 2019, p. 140-141.

${ }^{7}$ DANTAS, San Tiago. Programa de Direito Civil I, Rio de Janeiro: Rio, 2001.

${ }^{8}$ GONÇALVES, Carlos Roberto. Direito Civil Brasileiro: Responsabilidade. 7. ed. São Paulo: Saraiva, 2011, p. 24.

${ }^{9}$ DINIZ, Maria Helena. Curso de Direito Civil Brasileiro: Responsabilidade Civil. 17. ed. São Paulo: Saraiva, 2003, p.15.
} 
Nesse viés, observa-se que através da responsabilidade civil do agente nasce o direito à reparação, proporcionando a possibilidade ao lesado de acionar a Justiça, com o intuito de retirar do patrimônio do agente causador a quantia suficiente para reposição das perdas ocorridas ou para a compensação de danos morais sofridos.

Assim também se verifica tal entendimento na obra de Carlos Bittar $^{10}$, que leciona:

“A lesão a elementos integrantes da esfera jurídica alheia acarreta ao agente a necessidade de reparação dos danos provocados. É a responsabilidade civil, ou obrigação de indenizar, que compele o causador a arcar com as consequências advindas da ação violadora, ressarcindo os prejuízos de ordem moral ou patrimonial, decorrente de fato ilícito próprio, ou de outrem a ele relacionado."

O instituto da responsabilidade civil é parte integrante do direito obrigacional, sendo a obrigação, de forma sucinta, o direito do credor contra o devedor, tendo por objeto determinada prestação. $^{11}$

Nos primórdios da civilização humana o que prevalecia era a vingança coletiva, que se caracterizava pela reação de um grupo contra um agressor pela sua ofensa. Carlos Roberto Gonçalves ${ }^{12}$, explica sobre a evolução histórica da responsabilidade civil:

“[...] Não se cogitava em fator culpa. O dano provocava reação imediata da outra parte, da forma instintiva e brutal do ofendido, não havendo regras, nem limitações. Não imperava ainda o Direito. Dominava então a vingança privada, forma primitiva, selvagem, mas humana, da reação espontânea e natural contra o mal sofrido. Solução comum a todos os povos em suas origens, para a reparação do mal pelo mal. "

Com isso, a evolução da responsabilidade civil surge diante da necessidade de punir quem comete um dano de uma forma mais civilizada. Então, a sociedade caminhou para uma busca do mal pelo mal, ou seja, as pessoas passaram a buscar justiça pelas próprias mãos, dando surgimento a Lei do Talião. ${ }^{13}$ Compreende-se que pela Lei do Talião, a justiça do lesado era realizada por suas próprias mãos. A vítima aplicava ao seu ofensor dano parecido com o que havia sofrido.

\footnotetext{
${ }^{10}$ BITTAR, Carlos Alberto. Curso de direito civil. 1. ed. Rio de Janeiro: Forense, 1994, p. 561.

${ }^{11}$ GONÇALVES, Carlos Roberto. Direito Civil Brasileiro: Responsabilidade Civil, v. IV, 4. ed., São Paulo: Saraiva, 2009.

${ }^{12}$ Idem, 1996. p. 04.

${ }^{13}$ DINIZ, Maria Helena. Curso de Direito Civil Brasileiro: Responsabilidade Civil. 17. ed., v.7., São Paulo: Saraiva, 2003, p. 09-10.
} 
A vingança privada seria aquela "forma primitiva, selvagem talvez, mas humana, da reação espontânea e natural contra o mal sofrido; solução comum a todos os povos nas suas origens, para a reparação do mal pelo mal"14.

Sobre a evolução da responsabilidade a autora Maria Helena Diniz ensina:

\begin{abstract}
“A responsabilidade civil apresenta uma evolução pluridimensional, pois sua expansão se deu quando sua história, aos seus fundamentos, a sua extensão ou área de incidência (número de pessoas responsáveis e fatos que ensejam a responsabilidade) e a sua profundidade ou densidade (extinção e reparação). "15
\end{abstract}

Ainda sobre evolução da responsabilidade civil, afirma Maria Helena Diniz que, nos primórdios da civilização humana, dominava a vingança coletiva, que se caracterizava pela reação conjunto de um grupo contra o agressor pela ofensa de um de seus componentes. ${ }^{16}$

O dever de reparar o prejuízo causado a outrem sempre existiu, realizado muitas vezes com o próprio corpo, com a evolução dos tempos, a reparação primitiva não deveria mais recair sobre a integridade física daquele que comete o dano, e sim sobre o patrimônio dele existente.

Nesse sentido, Maria Helena Diniz reforça essa tese da seguinte forma:

\begin{abstract}
"Depois desse período há o da composição, ante a observância do fato de que seria mais conveniente entrar em composição com o autor da ofensa - para que ele reparasse o dano mediante prestação da poena (pagamento de certa quantia em dinheiro), a critério da autoridade pública, se o delito fosse público (perpetrado contra direitos relativos a res pública) e do lesado, se se tratasse de delito privado (efetivado contra interesse de particulares) - do que cobra a retaliação, porque esta não reparava dano algum, ocasionando na verdade duplo dano: o da vítima e o de seu ofensor, depois de punido. "17
\end{abstract}

A lex aquiliade damono trouxe a ideia de culpa como fundamento da responsabilidade, enfatizando a ideia de reparação pecuniária do dano impondo ao patrimônio do lesante que suportasse os ônus da reparação. ${ }^{18}$

Atualmente, o Código Civil vigente na legislação brasileira é o de 2002. Ele recepciona duas teorias (subjetiva e objetiva) que explicam os critérios para auferir a responsabilidade ao possível causador de um dano, tendo em vista a reparação conforme o tipo de dano causado.

\footnotetext{
${ }^{14}$ GONÇALVES, Carlos Roberto. Direito Civil Brasileiro: Responsabilidade Civil. 10. ed. São Paulo: Saraiva, 2015 , p. 266.

15 DINIZ, op. cit., p. 09.

${ }^{16}$ Ibidem.

${ }^{17}$ DINIZ, Maria Helena. Curso de Direito Civil Brasileiro: Responsabilidade Civil. 17. ed., v.7., São Paulo: Saraiva, 2003, p. 10.

${ }^{18}$ KFOURI NETO, Miguel. Responsabilidade Civil do Médico. 5. ed. São Paulo: Revista dos Tribunais, 2003. p. 203.
} 


\subsection{FUNDAMENTOS NO CÓDIGO CIVIL E NO CÓDIGO DE DEFESA DO CONSUMIDOR}

No tocante à responsabilidade civil, o Código Civil de 2002 tem como principais dispositivos na parte geral, os arts. 186 a 188 e, na parte especial, com relação a responsabilidade contratual, o art. 389, e dois capítulos a obrigação de indenizar e a indenização, sob o título de responsabilidade civil. ${ }^{19}$

O art. 186 do Código Civil dispõe que: “Aquele que, por ação ou omissão voluntária, negligência ou imprudência, violar direito e causar dano a outrem, ainda que exclusivamente moral, comete ato ilícito".

A responsabilidade civil, busca a partir de um ato ilícito ou ilícito, restaurar um equilíbrio moral e patrimonial desfeito. Portanto, o objetivo da responsabilidade civil é restituir o dano por completo, isto é, a reposição completa da vítima a situação anterior a lesão, buscando uma situação material correspondente ou através de uma indenização mais próxima possível o valor do prejuízo sofrido.

Assim, tem a responsabilidade civil basicamente duas funções: a de garantir o direito do lesado a segurança; e, o de servir como sanção civil de natureza compensatória, mediante a reparação do dano causado a vítima, punindo o lesante e desestimulando a pratica de atos lesivos.

Nos artigos 927 e 943 do Código Civil de 2002 está prevista a obrigação de indenizar. Esse dever surge a partir do momento que é causado um dano ao patrimônio jurídico, devendo o mesmo ser reparado. Para que surja o real dever de indenizar fazem-se necessários os elementos: ação ou omissão, praticados por algum sujeito de direito, caracterizados pelo legislador como: culpa, dolo, equidade, boa-fé objetiva, um dano e, por fim, um nexo de causalidade que liga o efeito a causa.

Nas palavras de Patrick L. Silva ${ }^{20}$ : "não basta à prática de um ato ilícito ou ainda a ocorrência de um evento danoso, mas que entre estes exista a necessária relação de causa e efeito." Assim, analisando o nexo de causalidade da responsabilidade civil é possível chegar à conclusão de se o agente agiu ou não com culpa para se chegar naquele resultado.

\footnotetext{
${ }^{19}$ GONÇALVES, Carlos Roberto. Direito Civil Brasileiro: Responsabilidade Civil, v. IV, 4. ed., São Paulo: Saraiva, 2009.

${ }^{20}$ SILVA, Patrick L. Fatos Jurídicos: teoria e prática. Porto Alegre: verbo jurídico, 2011, p. 133.
} 
À luz do Código de Defesa do Consumidor (Lei n. 8.078/90 ${ }^{21}$ ), em seu artigo $2^{\circ}$, "consumidor é toda pessoa física ou jurídica que adquire ou utiliza produto ou serviço como destinatário final. " E, seu parágrafo único declara que "equipara-se a consumidor a coletividade de pessoas, ainda que indetermináveis, que haja intervindo nas relações de consumo. "

Destacando-se, ao declarar que consumidor é aquele que utiliza serviços, o Código de Defesa do Consumidor incluiu a atividade médica no rol das relações de consumo, adotando, assim, a teoria da responsabilidade subjetiva, conferindo ao paciente o status de parte hipossuficiente e fazendo da relação médico-paciente um objeto a ser tutelado pela lei, facilitando, dessa maneira, a solução dos litígios relacionados.

\title{
2.3 RESPONSABILIDADE SUBJETIVA E OBJETIVA
}

No Brasil, o Código Civil classifica a responsabilidade civil, conforme o fundamento da imputação da obrigação de indenizar, em responsabilidade subjetiva, ou culposa, na qual prevalece o princípio da culpa, e em objetiva, ou pelo risco, onde o princípio do risco prevalece. $^{22}$

Segundo entendimento de Rogério Marrone de Castro Sampaio:

\begin{abstract}
"A responsabilidade civil pode ser subjetiva ou objetiva. A primeira é baseada na teoria da culpa, que considera a culpa como principal fundamento da responsabilidade civil. Se não há culpa, não há responsabilidade. Desse modo, a prova da culpa é essencial para que o dano seja indenizável. Portanto, a vítima somente terá direito à reparação do dano se provar a culpa do agente. A segunda (responsabilidade objetiva) independe de culpa, pois se satisfaz com o dano e o nexo de causalidade. Essa responsabilidade tem como base a teoria do risco que pressupõe que todo dano é indenizável, independentemente de culpa. Sendo assim, a culpa do agente não precisa ser provada para que ele tenha que reparar o dano causado. "23
\end{abstract}

Analisando o artigo 186 do Código Civil, a responsabilidade civil subjetiva é diferente da objetiva quanto à forma, sendo que não é correto afirmar que são de espécies diferentes, já que, em ambas, se enquadram os deveres de indenizar e reparar o dano causado, distinguindose no que diz respeito à existência ou não de culpa por parte do agente que causou o dano experimentado pela vítima.

\footnotetext{
${ }^{21}$ BRASIL. Lei no ${ }^{0}$ 8.078, de 11 de setembro de 1990. Código de Defesa do Consumidor. Dispõe sobre a proteção do consumidor e dá outras providências. Disponível em: http://www.planalto.gov.br/ccivil_03/Leis/L8078.htm. Acesso em: 23 jan. 2020.

${ }^{22}$ MATIELO, Fabrício Zamprogna. Responsabilidade civil do médico. Porto Alegre: Sagra Luzzatto, 1998, p. 19.

${ }^{23}$ SAMPAIO, Rogério Marrone de Castro. Responsabilidade civil. 2. ed. São Paulo: Atlas, 2002, p. 26.
} 
Nos ensinamentos de Fernando Noronha:

\begin{abstract}
"Esta responsabilidade nasce de atos ilícitos, que são ações ofensivas de direitos alheios, proibidas pela ordem jurídica e imputáveis a uma pessoa de quem se possa afirmar ter procedido culposamente, ou mesmo de forma intencional. No seu âmbito, em casos especiais não é o lesado que tem de provar o dolo, ou a negligência, imprudência e imperícia do agente: são hipóteses em que incide sobre o agente uma presunção legal relativa (juris tantum) de culpa do agente, e por consequência em que este, para se libertar, tem de demonstrar que agiu com todos os cuidados que seriam exigíveis, embora sem ter necessidade de provar que o fato se deveu a caso fortuito ou de força maior. " 24
\end{abstract}

A característica dominante da doutrina objetiva é que o dano pode ser resultado de uma conduta eximida do elemento culpa. Portanto, o dever de indenizar não se vincula à ideia de comportamento culposo. A responsabilidade objetiva ao ver de Maria Helena Diniz é:

\begin{abstract}
"A atividade que gerou o dano é ilícita, mas, causou perigo a outrem, de modo que aquele que a exerce, por ter a obrigação de velar para que dela não resulte prejuízo, terá o dever ressarcitório, pelo simples implemento do nexo causal. A vítima deverá pura e simplesmente demonstrar o nexo de causalidade entre o dano e a ação que reduziu. Nela não se cogita a responsabilidade indireta, de tendência à solicitação dos riscos, nem do fortuito como excludente de responsabilidade. $" 25$
\end{abstract}

Na visão de Maria Helena Diniz, a responsabilidade subjetiva, é aquela pela qual o dano contra a vítima foi causado por culpa do agente, enquanto que a objetiva, por sua vez, configurase como sendo aquela que tem, por fundamento, a teoria do risco, onde não existe a obrigação de provar culpa para que prevaleça o dever de indenizar. Ela explica que: "a responsabilidade subjetiva se encontra justificada na culpa ou dolo por ação ou omissão, lesiva a determinada pessoa, desse modo a prova da culpa do agente será necessária para que surja o dever de reparar. , 26

Assim sendo, a teoria fundamenta a responsabilidade, pois na culpa que uma vez provada ou em certos casos presumida, dá ensejo a uma indenização. Já a responsabilidade civil objetiva, para ser caracterizada prescinde de culpa. Fundada no risco da atividade exercida pelo agente, a responsabilidade objetiva ignora se o ato do infrator foi doloso ou culposo, fazendose necessário apenas a existência do nexo de causalidade entre a conduta do agente e o dano sofrido, gerando assim o dever de indenizar.

\footnotetext{
${ }^{24}$ NORONHA, Fernando. Direito das Obrigações. Fundamentos do direito das obrigações: introdução à responsabilidade civil. São Paulo: Saraiva, 2003, p. 486.

${ }^{25}$ DINIZ, Maria Helena. Curso de Direito Civil Brasileiro: Responsabilidade Civil. 17. ed. São Paulo: Saraiva, 2003 , p. 52.

${ }^{26}$ DINIZ, op. cit., p. 54.
} 


\section{RESPONSABILIDADE CIVIL DO HOSPITAL}

\subsection{CONCEITO E OBRIGAÇÕES DO HOSPITAL}

Na definição de Aguiar Júnior o "hospital é uma universalidade de fato, formada por um conjunto de instalações, aparelhos, e instrumentos médicos e cirúrgicos destinados ao tratamento da saúde, vinculada a uma pessoa jurídica, sua mantenedora, mas que não realiza ato médico. "27

Segundo Maria Helena Diniz, o hospital possui várias obrigações, não somente de prestador de serviços médicos, como também de enfermagem, internação, ambulatório médico, laboratório, locação de quartos, cirurgia com equipe especializada, etc. ${ }^{28}$

\subsection{RESPONSABILIDADE CIVIL DO HOSPITAL PELO INSUCESSO DE CIRURGIAS}

A responsabilidade civil dos hospitais em face de seus pacientes, internos ou não, é contratual $^{29}$. José de Aguiar Dias afirma que se trata de uma obrigação semelhante à dos hoteleiros, cuja responsabilidade compreende os deveres de assistência médica e de hospedagem. ${ }^{30}$

\subsection{APLICAÇÃO DO CDC E CÓDIGO CIVIL NAS INSTITUIÇÕES HOSPITALARES}

Antes da entrada em vigor do Código de Defesa do Consumidor, a responsabilidade do hospital encontrava-se fundamentada no artigo 152, inciso III do Código Civil de 1916, que implicava na obrigação de o patrão responder pelo fato ilícito causado por seu preposto, a responsabilidade indireta, mantida pelo Código Civil de 2002.

\footnotetext{
${ }^{27}$ AGUIAR JUNIOR, Ruy Rosado de. Responsabilidade Civil do Médico. São Paulo: Revista dos Tribunais, v. 84, n. 718, 1995, p. 33.

${ }^{28}$ DINIZ, Maria Helena. Tratado teórico e prático dos contratos. 5. ed., v. 2, São Paulo: Saraiva, 2003, p. 589.

29 FRANCISCO, Caramuru Afonso. Responsabilidade Civil dos Hospitais, Clínicas e Prontos-socorros. In: BITTAR, Carlos Alberto (Coord.). Responsabilidade Civil Médica, odontológica e hospitalar. São Paulo: Saraiva, 1991, p. 195.

${ }^{30}$ DIAS, José de Aguiar. Da Responsabilidade Civil. 11. ed. Rio de Janeiro: Renovar, 2006, p. 486.
} 
Assim, com fulcro na Súmula n. 341 do Supremo Tribunal Federal o hospital responde se provada a negligencia, imprudência ou imperícia do médico, isto é, "presumida a culpa do patrão ou comitente pelo ato culposo do empregado ou preposto. "31

Então, mesmo depois da entrada em vigor do Código de Defesa do Consumidor, o hospital não responde objetivamente pelos serviços médicos prestados por profissionais que integram o seu quadro.

Nessa empreitada, defendem também Miguel Kfouri Neto ${ }^{32}$, Rui Rosado de Aguiar Junior $^{33}$ e Arnaldo Rizzardo ${ }^{34}$, dentre outros, que sustentam que a responsabilidade dos hospitais é subjetiva, sendo necessária a prova da culpa do médico pelo ato danoso, mesmo após a vigência do Código de Defesa do Consumidor.

\subsection{LIMITES DO NEXO CAUSAL EM CIRURGIAS MAL SUCEDIDAS}

Muitas são as teorias que buscam estipular limites ao nexo de causalidade. Na esfera cível, por não haver disposição expressa acolhendo uma ou outra doutrina, admite-se que a teoria prevalente é a da causalidade adequada, ocasião em que haverá responsabilização quando o ato do agente é potencialmente apto a produzir os efeitos danosos. Segundo Tepedino, "reduzse, dessa forma, a investigação do nexo causal à equação de probabilidade, sendo cada uma das diversas causas abstratamente considerada (...). " 35

Causa adequada, na visão de Fernando Noronha, "é a que, segundo as regras da experiência, não é indiferente ao surgir do dano. Em vez de se caracterizar a adequação, diz-se o que é causa inadequada: nesta formulação, a causalidade só fica excluída quando se trate de consequências indiferentes ao fato, estranhas ou extraordinárias. "36

$\mathrm{Na}$ doutrina brasileira, predomina o entendimento de que a teoria que melhor explica o nexo causal em matéria de responsabilidade civil é a da causalidade adequada, que nos ensina

\footnotetext{
${ }^{31}$ BRASIL. Supremo Tribunal Federal. Súmula $\mathbf{n}^{\circ}$ 341. Presumida a culpa do patrão ou comitente pelo ato culposo do empregado ou preposto. Disponível em: http://www.stf.jus.br/portal/jurisprudencia/menuSumarioSumulas.asp?sumula=2478. Acesso em: 13 jan. 2020. 32 KFOURI NETO, Miguel. Culpa médica e ônus da prova. 4. ed. São Paulo: Revista dos Tribunais, 2002, p. 365.

${ }^{33}$ AGUIAR JÚNIOR, Rui Rosado de. Responsabilidade civil do médico, São Paulo: Revista dos Tribunais, v. 84, n. 718, 1995, p. 41.

${ }^{34}$ RIZZARDO, Arnaldo. Responsabilidade Civil: lei n. 10.406/2002. 3. ed. Rio de Janeiro: Forense, 2007 , p. 317.

35 TEPEDINO, Gustavo. Notas sobre o nexo de causalidade. In: Temas de direito civil, tomo II. Rio de Janeiro: Renovar, 2006, p. 68.

${ }^{36}$ NORONHA, Fernando. Direito das obrigações, v. 1. São Paulo: Saraiva, 2003, p. 602.
} 
que nem todas as causas que concorrem para o resultado são equivalentes, sendo tão somente aquela que foi mais adequada a produzir o resultado. ${ }^{37}$

\section{CONSIDERAÇÕES FINAIS}

Este trabalho teve como objetivo estabelecer o limite do nexo de causalidade das instituições hospitalares nos casos em que procedimentos cirúrgicos malsucedidos por falta de escassez de recursos oferecidos pelo governo.

Sendo assim, vimos que a teoria adotada pela doutrina brasileira no âmbito da responsabilidade civil é a teoria da causalidade adequada, portanto, a responsabilidade do hospital é objetiva. Entretanto, é preciso a prova de que houve dano e que este decorreu de falhas no atendimento. A caracterização de sua responsabilidade pressupõe a demonstração de defeito no serviço, não bastando, destarte, a não obtenção dos resultados esperados do tratamento.

A Responsabilidade Civil deve seguir os fundamentos do direito comum, o dano praticado por qualquer sujeito de direito contra outro, deve ser reparado de alguma forma, independente de que espécie ele seja, se estiver dentro dos elementos jurídicos citados neste contexto. Caso o sujeito causador da conduta não seja responsável civilmente pela origem do ato, cabe o fundamento principal decidido pelo legislador para reparação do dano, dentro dos conformes, para que o cumprimento de qualquer obrigação seja designado ao seu verdadeiro responsável.

Em caso de responsabilidade do hospital, para ele haverá o direito de regresso contra o agente, que responderá por imprudência, negligência ou imperícia. Conforme o acórdão referido, ao pleitear a indenização contra o hospital, caberá ao paciente a prova de culpa do médico que o atendeu, salvo se obteve do juiz a inversão do ônus probatório. Nesse caso, o que virá a diferenciar uma instituição particular de uma pública é a pessoa passiva legítima para responder o quanto alegado.

Além disso, a responsabilidade civil surge com o dever de reparação quando existe lesão a elementos morais e materiais da esfera jurídica alheia, sendo que os pressupostos básicos para a sua caracterização são a existência do dano, do ato lesivo e do nexo causal. Nesse prisma, o profissional de medicina não pode se distanciar do conceito tradicional de culpa, no intuito de qualificação da conduta médica como lesiva e apta a gerar obrigação de indenização.

\footnotetext{
${ }^{37}$ SILVA, Clóvis do Couto e, Dever de indenizar. In: Revista de Jurisprudência do Tribunal de Justiça do Rio Grande do Sul: Porto Alegre, v.5, p. 3.
} 
Assim, em consonância com os comentários e opiniões dos doutrinadores pesquisados para o desenvolvimento desse trabalho, permite-se concluir que, em geral, a atividade medica é uma atividade de meio, onde o mesmo não fica comprometido a resultados pré-definidos, mas sim em empregar todo o seu conhecimento e as melhores técnicas disponíveis em prol de seu paciente. Além de que a responsabilidade do médico se funda em uma responsabilidade subjetiva, ou seja, baseada na culpa.

Destarte, o entendimento predominante, nesta questão, é de que hospital responde pelos atos médicos dos profissionais que o administram, bem como dos médicos que sejam seus empregados. Porém, não responde quando o médico simplesmente utiliza suas instalações apenas para a internação e tratamento dos seus pacientes.

Conclui-se, assim, que os hospitais apenas serão integrantes do polo passivo que postulem indenização por danos materiais ou morais, em ações decorrentes de erro cometido por médico, caso esses profissionais possuam algum vínculo empregatício com os hospitais. Nestes casos, a responsabilidade civil será apurada de forma subjetiva, isto é, mediante a verificação dos elementos culpa, nexo causal e danos.

Não obstante, é possível observar-se que a doutrina aponta a responsabilidade do hospital nas hipóteses de se ocorrer infecção hospitalar, quando este decorrer de condições insuficientes de ser evitada, de modo que se faz necessária a prova desses fatos para a procedência do pedido indenizatório. 


\section{REFERÊNCIAS}

AGUIAR JÚNIOR, Rui Rosado de. Responsabilidade civil do médico, São Paulo: Revista dos Tribunais, v. 84, n. 718, 1995.

BITTAR, Carlos Alberto. Curso de direito civil. 1. ed. Rio de Janeiro: Forense, 1994.

BRASIL. Lei $\mathbf{n}^{\mathbf{0}} \mathbf{. 8 . 0 7 8}$, de 11 de setembro de 1990. Código de Defesa do Consumidor. Dispõe sobre a proteção do consumidor e dá outras providências. Disponível em: http://www.planalto.gov.br/ccivil_03/Leis/L8078.htm. Acesso em: 23 jan. 2020.

BRASIL. Supremo Tribunal Federal. Súmula $n^{\circ}$ 341. Presumida a culpa do patrão ou comitente pelo ato culposo do empregado ou preposto. Disponível em: http://www.stf.jus.br/portal/jurisprudencia/menuSumarioSumulas.asp?sumula=2478. Acesso em: 13 jan. 2020.

CAVALIERI FILHO, Sérgio. Programa de Responsabilidade Civil, São Paulo: Atlas, 2008.

DANTAS, San Tiago. Programa de Direito Civil I, Rio de Janeiro: Rio, 2001.

DIAS, José de Aguiar. Da Responsabilidade Civil. 11. ed. Rio de Janeiro: Renovar, 2006.

DINIZ, Maria Helena. Curso de Direito Civil Brasileiro: Responsabilidade Civil. 17. ed., v.7., São Paulo: Saraiva, 2003.

DINIZ, Maria Helena. Tratado teórico e prático dos contratos. 5. ed., v. 2, São Paulo: Saraiva, 2003.

FRANCISCO, Caramuru Afonso. Responsabilidade Civil dos Hospitais, Clínicas e Prontossocorros. In: BITTAR, Carlos Alberto (Coord.). Responsabilidade Civil Médica, odontológica e hospitalar. São Paulo: Saraiva, 1991.

GAGLIANO, Pablo Stolze. Novo Curso de Direito Civil: Responsabilidade Civil. São Paulo: Saraiva, 2011.

GONÇALVES, Carlos Roberto. Direito Civil Brasileiro: Responsabilidade Civil. 7. ed., São Paulo: Saraiva, 2011.

GONÇALVES, Carlos Roberto. Direito Civil Brasileiro: Responsabilidade Civil, v. IV, 4. ed., São Paulo: Saraiva, 2009.

GONÇALVES, Carlos Roberto. Direito Civil Brasileiro: Responsabilidade civil. 6. ed. São Paulo: Saraiva, 1996.

GONÇALVES, Carlos Roberto. Direito Civil Brasileiro: Responsabilidade Civil. 10. ed. São Paulo: Saraiva, 2015.

KFOURI NETO, Miguel. Culpa médica e ônus da prova. 4. ed. São Paulo: Revista dos Tribunais, 2002. 
KFOURI NETO, Miguel. Responsabilidade Civil do Médico. 5. ed. São Paulo: Revista dos Tribunais, 2003.

MATIELO, Fabrício Zamprogna. Responsabilidade civil do médico. Porto Alegre: Sagra Luzzatto, 1998.

NORONHA, Fernando. Direito das Obrigações. Fundamentos do direito das obrigações: introdução à responsabilidade civil. São Paulo: Saraiva, 2003.

OLIVEIRA, Francisco Cardozo; OLIVEIRA, Nancy Mahra de Medeiros Nicolas. Leis, Serpentes e Baratas: análise reconstrutiva da sobrevivência das formas de fundamentos do Direito Moderno e seus efeitos na realidade brasileira. SEQUÊNCIA (UFSC), v. 40, 2019.

RAMOS, Edith Maria Barbosa; NETTO, Edson Barbosa de Miranda. O Federalismo E O Direito À Saúde Na Constituição Federal De 1988: Limites E Possibilidades Ao Estabelecimento De Um Autêntico Federalismo Sanitário Cooperativo No Brasil. Revista Juridica, [S.1.], v. 4, n. 49, p. 304 - 330, nov. 2017. ISSN 2316-753X. Disponível em: <http://revista.unicuritiba.edu.br/index.php/RevJur/article/view/2296/1426>. Acesso em: 14 abr. 2020. doi:http://dx.doi.org/10.21902/revistajur.2316-753X.v4i49.2296.

RIZZARDO, Arnaldo. Responsabilidade Civil: lei n. 10.406/2002. 3. ed. Rio de Janeiro: Forense, 2007.

SAMPAIO, Rogério Marrone de Castro. Responsabilidade civil. 2. ed. São Paulo: Atlas, 2002.

SILVA, Clóvis do Couto e, Dever de indenizar. In: Revista de Jurisprudência do Tribunal de Justiça do Rio Grande do Sul: Porto Alegre, v.5.

SILVA, Patrick L. Fatos Jurídicos: teoria e prática. Porto Alegre: verbo jurídico, 2011.

TEPEDINO, Gustavo. Notas sobre o nexo de causalidade. In: Temas de direito civil, tomo II. Rio de Janeiro: Renovar, 2006. 